\title{
STRESS ANALYSIS \\ PADA STAND SHOCK ABSORBERS SEPEDA MOTOR DENGAN MENGGUNAKAN SOFTWARE INVENTOR 2015
}

\author{
Asroni \\ Jurusan Teknik Mesin Universitas Muhammadiyah Metro Lampung \\ Jl.Ki Hajar Dewantara No.166 Kota Metro Lampung 34111, Indonesia \\ E-mail : asroni14@yahoo.com
}

\begin{abstract}
Abstrak
Dudukan Peredam Kejut (Stand Shock Absorbers) pada sepeda motor ada dua bagian atas dan bawah. Stand Shock Absorbers pada bagian atas terdapat batang poros berguna untuk menyatukan Shock Absorbers dengan rangka. Sementara yang di atas untuk memperkuat garpu agar tetap pada posisinya saat bekerja meredam getaran[1]. Pemodelan Stand Shock Absorbers menggunakan Metode Elemen Hingga dengan pembebanan sebesar 1000 N, $63.135 \mathrm{~N}$ ke arah vektor X dan 998.005 N ke arah vektor Y. material yang digunakan Besi Tuang dengan Massa Jenis $7.15 \mathrm{~g} / \mathrm{cm}^{3}$, Massa $0.0408248 \mathrm{~kg}$, Luas Area $5182.95 \mathrm{~mm}^{2}$ dan Volume $5709.76 \mathrm{~mm}^{3}$. Analisis tegangan menggunakan Software berbasis elemen hingga Inventor 2015. Hasil simulasi dapat ditarik kesimpulan bahwa Tegangan (Stress) yang terbesar (Maksimum Stress) terjadi ke arah vektor ZZ dengan nilai 40.3231 MPa, Regangan (Strain) yang terbesar (Maksimum Strain) terjadi ke arah vektor ZZ dengan nilai 0.000313922 ul dan Perpindahan (Displacement) yang terbesar terjadi ke arah vektor $\mathrm{Z}$ dengan nilai $0.0195378 \mathrm{~mm}$.
\end{abstract}

Kata Kunci : Stress Analysis, Stand Shock Absorbers, Peredam Kejut, Tegangan.

\section{PENDAHULUAN}

Suspensi berfungsi meredam getaran akibat jalan yang bergelombang, menjaga keseimbangan saat pengereman, dan menjaga keseimbangan saat menikung, sehingga pengendara merasa nyaman. Sepeda motor memiliki dua buah suspensi, yaitu suspensi depan dan belakang. Suspensi depan digunakan untuk meredam getaran yang ditimbulkan oleh roda depan dan pengereman roda depan. Penyusun peredam getaran pada suspensi depan, yaitu per, oli, dan tekanan angin dalam tabung suspensi. Tipe teleskop merupakan tipe suspensi depan yang digunakan pada sepeda motor modern masa kini. Suspensi belakang untuk meredam getaran osilasi yang dihasilkan oleh lengan ayun akibat getaran roda belakang. Suspensi belakang dapat diatur kekerasannya sesuai dengan beban yang dibawa oleh kendaraan[2].

Pembebanan pada sebuah komponen dapat dibagi dalam beberapa model pembebanan seperti pembebanan aksial, pembebanan dengan momen tekuk (bending moment), dan pembebanan dengan torsi. Model-model pembebanan ini pada suatu komponen, mempunyai pengaruh yang besar dalam desain suatu komponen[3]. Tegangan dan Regangan adalah konsep yang penting dalam peninjauan baik kekuatan maupun kekakuan. Keduanya merupakan konsekuensi yang tidak dapat dipisahkan dari bekerjanya suatu beban terhadap suatu bahan struktur. Tegangan dapat dianggap sebagai sebuah energi yang menahan beban; Regangan adalah ukuran deformasi yang terjadi sebagai akibat tegangan. Dalam suatu elemen struktur, tegangan adalah gaya dalam dibagi dengan luas penampang di mana gaya itu bekerja. Oleh karena itu, Tegangan dianggap sebagai efek bertumpuk dari tegangan.

Kekuatan bahan dapat diukur dengan tegangan maksimum yang dapat ditahannyakekuatan ini disebut juga tegangan runtuh (gagal). Kekuatan dari suatu elemen struktur diukur dari gaya dalam maksimum yang dapat ditahannya. Hal ini tergantung pada kekuatan bahan penyusunnya dan ukuran serta bentuk penampangnya. Kekuatan puncak dari elemen dicapai ketika tegangan melebihi tegangan runtuh dari bahan[4].

Autodesk Inventor memberikan alat simulasi terbaik terintegrasi di industri. digunakan untuk perhitungan; stres, defleksi, dan simulasi gerak yang memungkinkan ahli mesin untuk mengoptimalkan dan memvalidasi prototype digital sebelum produk dibuat. Simulasi dilakukan berdasarkan kendala di dunia nyata[5].

Dari latar belakang inilah perlu dilakukan penelitian mengenai tegangan, regangan dan 
perpindahan maksimum dan minimum dudukan peredam kejut (Stand Shock Absorbers dengan menggunakan Sotfware Inventor 2015.

\section{METODE PENELITIAN}

Metode penelitian yang digunakan adalah eksperimental semu (simulasi dengan komputer), material yang digunakan adalah Besi Tuang (Iron, Cast) dengan material properties yang dapat dilihat pada tabel berikut :

Tabel 1. Material

\begin{tabular}{lll}
\hline Name & Iron, Cast & \\
& Mass Density & $7.15 \mathrm{~g} / \mathrm{cm}^{3}$ \\
General & Yield Strength & $758 \mathrm{MPa}$ \\
& Ultimate Tensile Strength & $884 \mathrm{MPa}$ \\
& Young's Modulus & $120.5 \mathrm{GPa}$ \\
\multirow{2}{*}{ Stress } & Poisson's Ratio & $0.3 \mathrm{ul}$ \\
& Shear Modulus & $46.3462 \mathrm{GPa}$ \\
\hline
\end{tabular}

Tabel 2. Phytsical

\begin{tabular}{ll}
\hline Material & Iron, Cast \\
Density & $7.15 \mathrm{~g} / \mathrm{cm}^{3}$ \\
Mass & $0.0408248 \mathrm{~kg}$ \\
Area & $5182.95 \mathrm{~mm}^{2}$ \\
Volume & $5709.76 \mathrm{~mm}^{3}$ \\
Center of & $\mathrm{x}=0.000000000165706 \mathrm{~mm}$ \\
Gravity & $\mathrm{y}=-9.52699 \mathrm{~mm}$ \\
& $\mathrm{z}=0 \mathrm{~mm}$ \\
\hline
\end{tabular}

\section{Pemodelan Elemen Hingga}

Untuk pemodelan spesimen dudukan peredam kejut (Stand Sock Absorbers) dapat dilihat pada Tabel 3.

Tabel 3. Mesh Settings

\begin{tabular}{ll}
\hline Avg. Element Size (fraction of model diameter) & 0.1 \\
Min. Element Size (fraction of avg. size) & 0.2 \\
Grading Factor & 1.5 \\
Max. Turn Angle & $60 \mathrm{deg}$ \\
Create Curved Mesh Elements & Yes
\end{tabular}

Gaya yang diberikan searah vektor Y sesuai dengan arah pembebanan. Input gaya sebesar $1000 \mathrm{~N}$.

Tabel 4. Gaya (Force)

\begin{tabular}{ll}
\hline Load Type & Force \\
Magnitude & $1000 \mathrm{~N}$ \\
Vector $X$ & $63.135 \mathrm{~N}$ \\
Vector $Y$ & $998.005 \mathrm{~N}$ \\
Vector $Z$ & $0 \mathrm{~N}$ \\
\hline
\end{tabular}

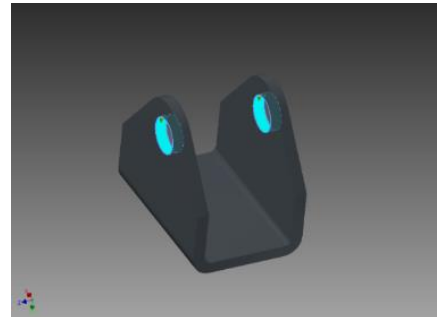

Gambar 1. Selected Face of Force

Titik pegangan (Fixed Constrain) adalah tempat barang dikunci dudukannya sehingga tidak bisa bergerak ke mana-mana, titik pegangan Stand Shock Absorbers adalah bagian bawah yang berhubung dengan Lengan Ayun yang ditunjukkan warna Light Cyan.

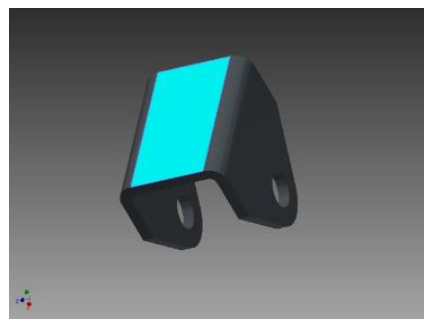

Gambar 2. Selected Face of Fixed Constrain HASIL DAN PEMBAHASAN

Dengan feature Generate Report yang disediakan, maka didapat rangkuman nilai hasil simulasi berupa tabel dan gambar.

Tabel 6. Result Summary

\begin{tabular}{|c|c|c|}
\hline Name & Minimum & Maximum \\
\hline Volume & $5709.76 \mathrm{~mm}^{3}$ & \\
\hline Mass & $0.0408248 \mathrm{~kg}$ & \\
\hline Von Mises Stress & $0.0906865 \mathrm{MPa}$ & $47.4662 \mathrm{MPa}$ \\
\hline 1st Principal Stress & $-20.694 \mathrm{MPa}$ & $43.2816 \mathrm{MPa}$ \\
\hline 3rd Principal Stress & $-61.9779 \mathrm{MPa}$ & $4.68979 \mathrm{MPa}$ \\
\hline Displacement & $0 \mathrm{~mm}$ & $0.0201715 \mathrm{~mm}$ \\
\hline Safety Factor & $15 \mathrm{ul}$ & $15 \mathrm{ul}$ \\
\hline Stress $X X$ & $-24.708 \mathrm{MPa}$ & $14.5498 \mathrm{MPa}$ \\
\hline Stress $X Y$ & $-12.1666 \mathrm{MPa}$ & $11.2745 \mathrm{MPa}$ \\
\hline Stress $X Z$ & $-5.872 \mathrm{MPa}$ & $5.90562 \mathrm{MPa}$ \\
\hline Stress $Y Y$ & $-41.4373 \mathrm{MPa}$ & $10.1642 \mathrm{MPa}$ \\
\hline Stress $Y Z$ & $-20.7401 \mathrm{MPa}$ & $20.8259 \mathrm{MPa}$ \\
\hline Stress ZZ & $-41.7694 \mathrm{MPa}$ & $40.3231 \mathrm{MPa}$ \\
\hline X Displacement & $-0.000174233 \mathrm{~mm}$ & $0.00131893 \mathrm{~mm}$ \\
\hline Y Displacement & $-0.0000331628 \mathrm{~mm}$ & $0.00507631 \mathrm{~mm}$ \\
\hline Z Displacement & $-0.0195547 \mathrm{~mm}$ & $0.0195378 \mathrm{~mm}$ \\
\hline Equivalent Strain & $0.000000653046 \mathrm{ul}$ & $0.000353794 \mathrm{ul}$ \\
\hline 1st Principal Strain & $0.0000000150151 \mathrm{ul}$ & $0.000322389 \mathrm{ul}$ \\
\hline 3rd Principal Strain & $-0.000406277 \mathrm{ul}$ & $-0.000000325144 \mathrm{ul}$ \\
\hline Strain $X X$ & $-0.000112562 \mathrm{ul}$ & $0.000109172 \mathrm{ul}$ \\
\hline Strain $X Y$ & -0.000131258 ul & $0.000121633 \mathrm{ul}$ \\
\hline Strain XZ & $-0.0000633494 \mathrm{ul}$ & $0.000063712 \mathrm{ul}$ \\
\hline Strain $Y Y$ & $-0.000180482 \mathrm{ul}$ & $0.0000780718 \mathrm{ul}$ \\
\hline Strain $Y Z$ & $-0.000223752 \mathrm{ul}$ & $0.000224678 \mathrm{ul}$ \\
\hline Strain ZZ & $-0.000302878 \mathrm{ul}$ & $0.000313922 \mathrm{ul}$ \\
\hline
\end{tabular}


Material dikatakan mulai luluh ketika tegangan Von Mises mencapai nilai kritis yang diketahui sebagai Yield Strength[6,7]. Maximum Principal Stress yang menunjukkan secara spesifik bagian yang paling tegang, warna merah merupakan bagian yang paling tegang[8]. Minimum Principal Stress yang menunjukkan secara spesifik bagian yang paling rileks, warna kuning merupakan bagian yang paling rileks[9]. Safety Factor yang menunjukkan bagian yang aman ketika diberi gaya, bagian yang paling aman adalah bagian yang berwarna Biru Tua[10]. Safety factor ( $F d$ atau $S f$ harus bernilai di atas 1).

Tabel 5. Reaction Force and Moment on Constraints

\begin{tabular}{|c|c|c|c|c|}
\hline \multirow[b]{2}{*}{ Constraint Name } & \multicolumn{2}{|c|}{ Reaction Force } & \multicolumn{2}{|c|}{ Reaction Moment } \\
\hline & Magnitude & $\begin{array}{l}\text { Component } \\
(X, Y, Z)\end{array}$ & Magnitude & $\begin{array}{l}\text { Component } \\
(X, Y, Z)\end{array}$ \\
\hline \multirow{3}{*}{$\begin{array}{l}\text { Fixed } \\
\text { Constraint:1 }\end{array}$} & \multirow{3}{*}{$1000 \mathrm{~N}$} & $-63.1348 \mathrm{~N}$ & \multirow{3}{*}{$1.514 \mathrm{~N} \mathrm{~m}$} & $0 \mathrm{Nm}$ \\
\hline & & $-998.005 \mathrm{~N}$ & & $0 \mathrm{Nm}$ \\
\hline & & $0 \mathrm{~N}$ & & $-1.514 \mathrm{Nm}$ \\
\hline
\end{tabular}

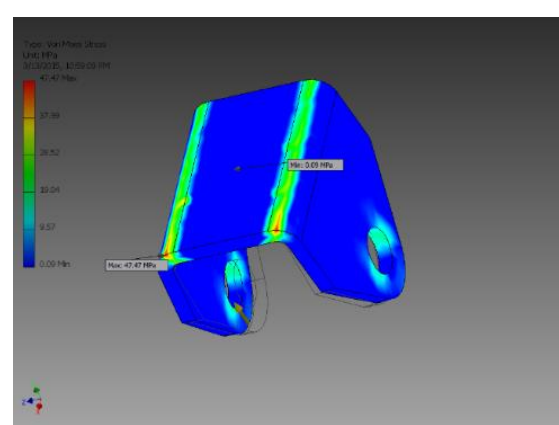

Gambar 3. Von Mises Stress

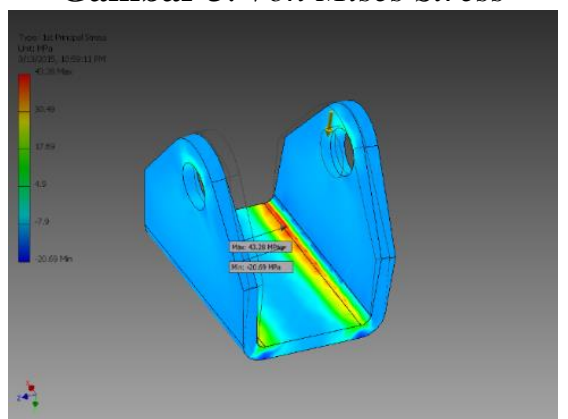

Gambar 4. $1^{\text {st }}$ Principal Stress

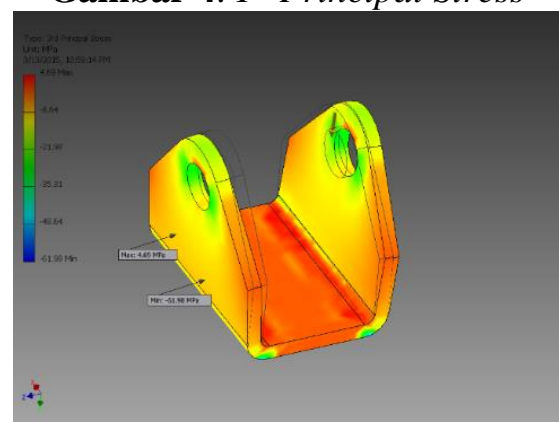

Gambar 5. $3^{\text {rd }}$ Principal Stress

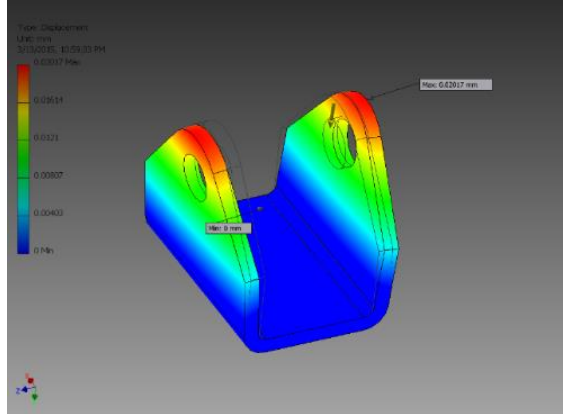

Gambar 6. Displacement

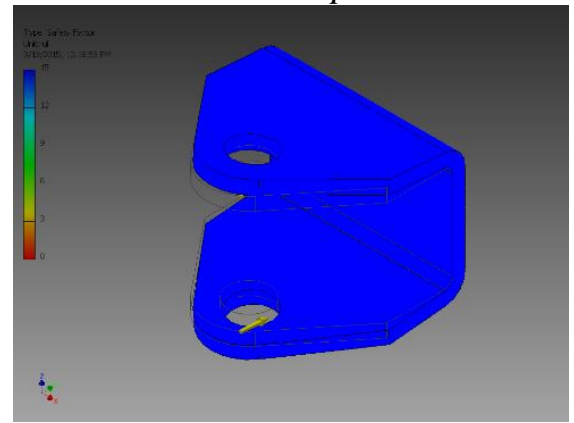

Gambar 7. Safety Factor

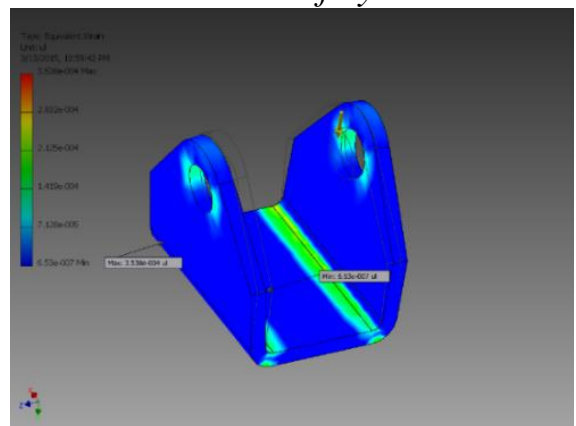

Gambar 8. Equivalent Strain

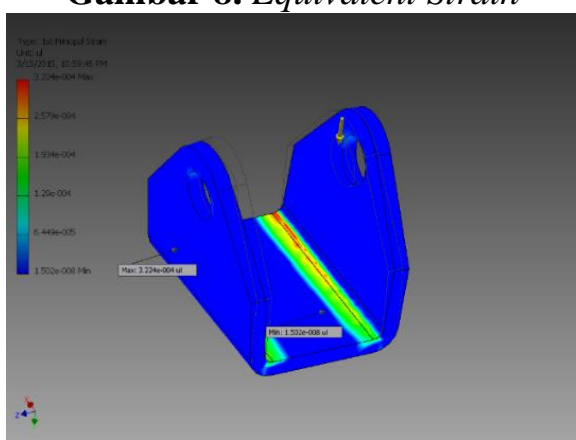

Gambar 9. $1^{\text {st }}$ Principal Strain

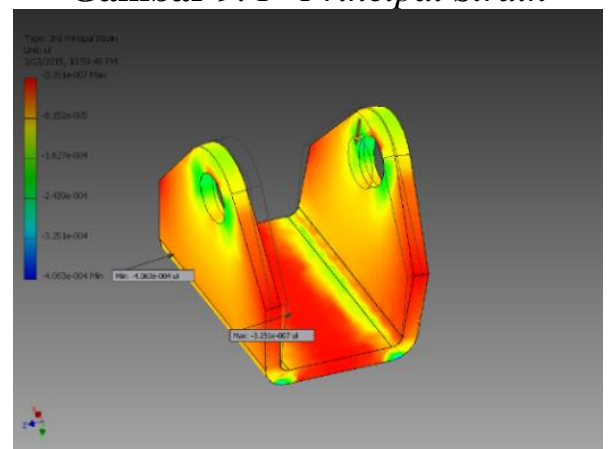

Gambar 10. $3^{\text {rd }}$ Principal Stress 


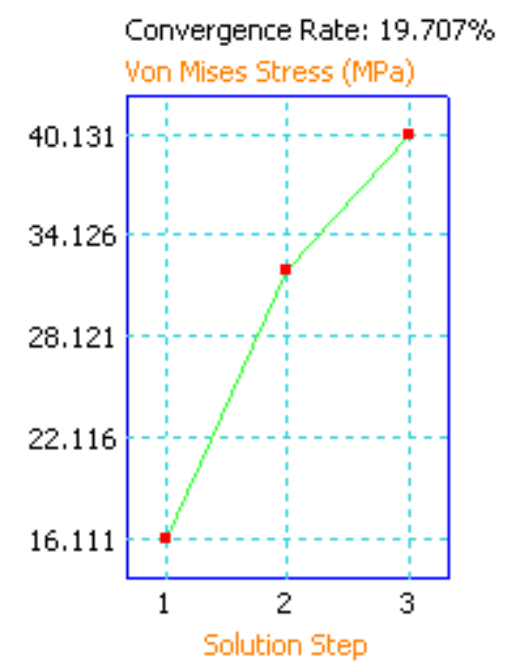

Gambar 11. Laju Konvergensi Tegangan Luluh

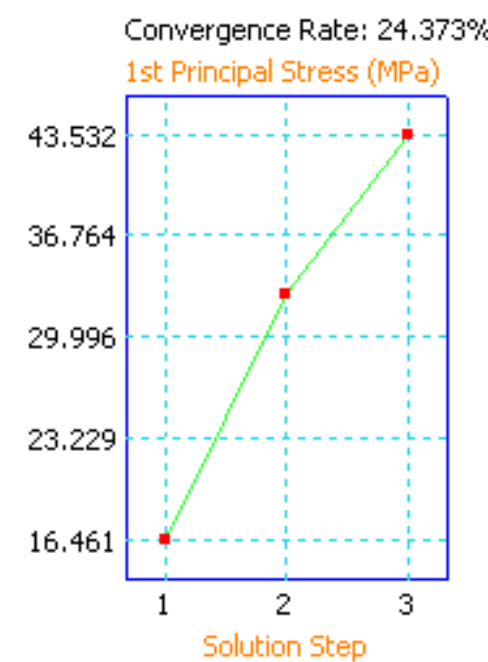

Gambar 12. Laju Konvergensi Tegangan Maksimum

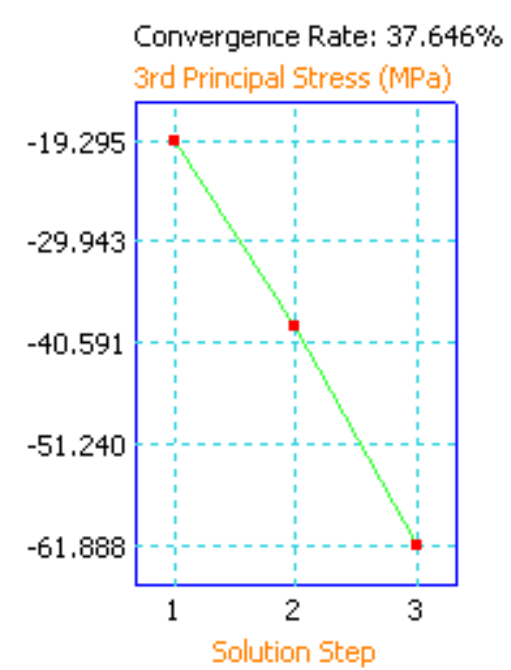

Gambar 13. Laju Konvergensi Tegangan Minimum

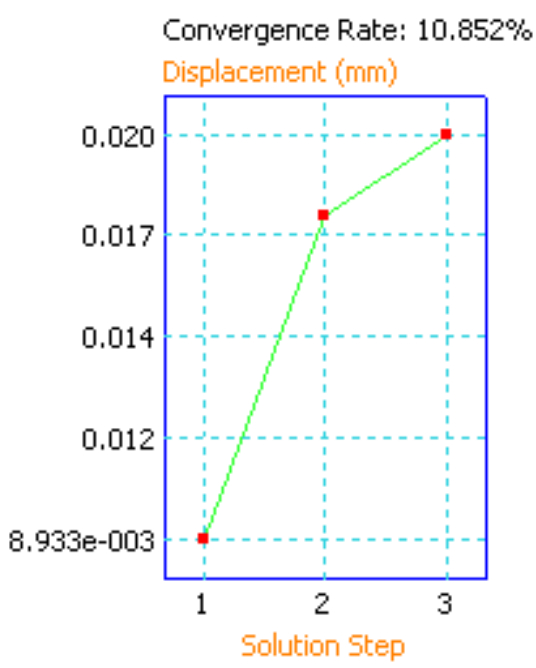

Gambar 14. Laju Konvergensi Perpindahan

Laju konvergensi tegangan adalah laju dimana pada saat terjadi tegangan arah tegangannya menyebabkan slip atau deformasi yang belum searah, apabila diterapkan pada durasi waktu tertentu maka perlahan-lahan arah pengaruh gaya tegangan akan searah pada bidang deformasi atau slip. Semakin cepat searah, maka laju konvergensinya juga semakin besar[11].

\section{KESIMPULAN}

Dari hasil simulasi yang telah dilakukan, tegangan (Stress) yang terbesar (Maksimum Stress) terjadi ke arah vektor ZZ dengan nilai 40.3231 MPa. Sedangkan tegangan (Stress) yang terkecil (Minimum Stress) terjadi ke arah vektor $\mathrm{ZZ}$ dengan nilai -41.7694 MPa.

Regangan (Strain) yang terbesar (Maksimum Strain) terjadi ke arah vektor ZZ dengan nilai 0.000313922 ul. Sedangkan Regangan (Strain) yang terkecil (Minimum Strain) terjadi ke arah vektor ZZ dengan nilai $0.000302878 \mathrm{ul}$.

Perpindahan (Displacement) yang terbesar terjadi ke arah vektor $Z$ dengan nilai 0.0195378 $\mathrm{mm}$. Sedangkan Perpindahan (Displacement) yang terkecil terjadi ke arah vektor $Z$ dengan nilai $-0.0195547 \mathrm{~mm}$.

\section{DAFTAR PUSTAKA}

1. Setiawan, Acip. 2007. Sohor Jadi Modfikasi Motor. Gramedia Pustaka Utama. Jakarta.

2. Suwarto. Toto. 2008. Mencari dan Memperbaiki Kerusakan Sepeda Motor 4 tak Kawan Pustaka. Jakarta.

3. Ashby, Michael F. 2005. Materials Selection In Mechanical Design 3th Edition. Pergamon Press.

4. Macdonald. Angus J. 2002. Struktur dan Arsitektur Edisi Kedua. Erlangga. Jakarta. 
5. Autodesk. 2010. Learning Autodesk Inventor 2010. Autodesk, Inc. San Rafael. USA

6. Liu, G.R. and Quek S.S. 2003. Finite Element Method:A Practical Course. Butterworth-Heinemann. Jordan Hill.

7. Huke, Baker. 1999. ASM Specialty Handbook: Magnesium and Magnesium Alloys. ASM International. Handbook Committee.

8. Punmia. Dr. B.C. 2002. Mechanics of Materials. Firewall Media. An Imprint of Laxmi Publications Pvt. Ltd.

9. Gere, James. 2011. Mechanics of

Materials, Brief Edition. Cengage Learning. USA.

10. Rao. D.S. 2002. Introduction to Strength of Materials. Universities Press. India.

11. Ding, Jiu. 2010. Statistical Properties of Deterministic Systems. Springer Science \& Business Media. Beijing. 